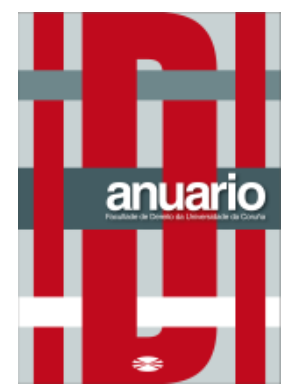

Anuario da Facultade de Dereito da Universidade da Coruña

Vol. 23 (2019), pp. 50-69

ISSNe: 2530-6324 || ISSN: 1138-039X

DOI: https://doi.org/10.17979/afdudc.2019.23.0.6011

\title{
REFLEXIONES EN TORNO A LA VALORACIÓN DE LA PRUEBA DE RECONOCIMIENTO JUDICIAL EN EL PROCESO CIVIL ${ }^{1}$
REFLECTIONS ON THE ASSESSMENT OF THE JUDICIAL RECOGNITION EVIDENCE

\begin{abstract}
CARLOS DE MIRANDA VÁZQUEZ ${ }^{2}$
Doctor en Derecho. Profesor de Derecho Procesal de la Universidad Internacional de

Cataluña (UIC)
\end{abstract}

\begin{abstract}
Resumen: El presente estudio aborda la espinosa cuestión de la valoración de la prueba de reconocimiento judicial. La falta de una norma que siente criterios valorativos ha alimentado toda suerte de especulaciones sobre si hay tal valoración y si la hubiera si se trata de un acto de decisión judicial libérrimo. La incertidumbre sobre dicho aspecto se acrecienta cuando se aprecia que tan siquiera es pacífico cuál sea el concreto objeto de la actividad valorativa, si es que la hay. Toda esta polémica tiene repercusiones prácticas, entre las que destaca la posibilidad efectiva de sujetar su valoración a algún tipo de control en sede de recursos. Finalmente, todo se complica cuando el juez perceptor y el sentenciador son distintos.
\end{abstract}

Palabras clave: prueba, reconocimiento judicial, valoración, recursos.

Abstract: The present study deals with the thorny question of the assessment of the judicial recognition evidence. The lack of a concrete rule that states the standard of said evidence has produced all sorts of speculations about whether there exists such an assessment and, in the event that it exists, if it is an act of a real free judicial decision. The uncertainty about this aspect is increased when it is appreciated that it is not even peaceful which is the concrete object of the activity of assessment, if there is any. All

\footnotetext{
1 Este trabajo se enmarca en el proyecto de I + D del Ministerio de Economía y Competitividad «Conflictos de Derechos: Tipologías, Razonamientos, Decisiones» (DER2016-74898-C2-1-R), cuyo investigador principal es el Prof. Dr. Juan Antonio García Amado, y en las actividades de investigación del grupo de investigación consolidado de la AGAUR sobre «Derecho Probatorio» (2014SGR438), cuyo investigador principal es el Prof. Dr. Joan Picó i Junoy.

${ }^{2}$ Quiero agradecer expresamente las atinadas observaciones del profesor Dr. Andino López, que, sin duda alguna, han contribuido significativamente a mejorar la versión inicial de este trabajo.
} Anu Fac Der UDC, 2019, 23: 50-69 
this controversy has practical repercussions, among which we highlight the effective possibility of subjecting said assessment to some type of control in any appeal of the judgment. Finally, everything gets complicated when the judge that proceeds with the evidence and the judge that issues judgment is a different one.

Keywords: evidence, judicial recognition, assessment, appeals.

Sumario: I. INTRODUCCIÓN. II. APROXIMACIÓN EPISTÉMICA A LA PRUEBA DE RECONOCIMIENTO JUDICIAL. III. LA VALORACIÓN DE LA PRUEBA DE RECONOCIMIENTO JUDICIAL A FONDO. IV. MOTIVACIÓN $Y$ CONTROL DEL JUICIO VALORATIVO DE LA PRUEBA DE RECONOCIMIENTO JUDICIAL. V. ¿QUÉ TRASCENDENCIA TIENE QUE EL JUEZ PERCEPTOR SEA DISTINTO AL JUEZ SENTENCIADOR, EN TÉRMINOS VALORATIVOS? VI. BIBLIOGRAFÍA.

\section{INTRODUCCIÓN}

De primeras, puede parecer que se trata de una cuestión teorética o meramente especulativa, con escasa repercusión práctica. Sin embargo, tras una mirada detenida, como explicaremos, el asunto cobra interés ${ }^{3}$.

La primera gran cuestión que nos sale al paso es la que atañe a si esta prueba lleva aparejada valoración. O, mejor dicho, si es objeto de valoración por parte del juez. Porque, según cómo se mire, podría parecer que el juez — que tiene contacto directo e inmediato con la realidad ${ }^{4}$ - no debe valorarse a sí mismo, según lo ha percibido y lo ha expresado oralmente ${ }^{5}$. Por tanto, (se) asume el resultado probatorio sin más ni más ${ }^{6}$.

Si llegásemos a la conclusión de que sí valora -lo que sea que valore-, nos saldría al paso otro inconveniente. A diferencia de lo que acontece con el resto de medios de prueba, en la disciplina del reconocimiento no existe un precepto que indique cómo deba el juez valorar la prueba. No se trata en absoluto de un "pseudoproblema», porque dicho vacío puede interpretarse como un cheque en blanco para el juez, al que se le permite obrar a discreción en relación con esta concreta prueba ${ }^{7}$. Cuando el legislador

\footnotetext{
${ }^{3}$ Mi interés en la cuestión nació al redactar el capítulo relativo a la prueba de reconocimiento judicial en la obra VV. AA., Práctica Procesal Civil (J. E. Corbal Fernández, P. Izquierdo Blanco y J. Picó i Junoy, Dirs.), tomo V, $23^{\mathrm{a}}$ ed., Barcelona, 2014, pp. 4115-4167.

${ }^{4}$ Cfr. ABEL LLUCH, X., Derecho probatorio, Barcelona, 2012, pp. 1044-1045.

5 Como habrían sostenido JIMÉNEZ CONDE y SERRA DOMÍNGUEZ, según expone NIEVA FENOLL, en su trabajo La valoración de la prueba, Madrid, 2010, p. 334.

${ }^{6}$ Idem.

${ }^{7}$ Cfr. STS, Sala $1^{\mathrm{a}}$, de 16 de abril de 1990 , fj $7^{\circ}$ (RJ 1990, 2719).
} 
ha querido — que es en el resto de $\operatorname{casos}^{8}$ — , ha sentado normativamente la obligación del juez de valorar la prueba con arreglo a las reglas de la sana crítica. Esta omisión normativa para algunos es un signo evidente de que aquí no hay valoración que valga ${ }^{9}$ - porque de lo contrario el legislador hubiera establecido cómo debe ser ésta ${ }^{10}$-, aunque para otros obedece a un simple descuido ${ }^{11}$.

Sea como fuere, todo lo anterior tiene graves repercusiones prácticas para los justiciables en el terreno del control de las decisiones judiciales adoptadas en relación con esta prueba y los resultados que arroje. Si no hay valoración y el juez asume sin pestañear lo que resulte de su ejercicio perceptivo, tampoco habrá control posible sobre esta actividad, puramente mecánica, lo que desemboca en que una parcela de la actuación judicial resulte exenta de control, lo cual es de todo punto inadmisible.

Si de lo contrario asumimos que sí hay valoración, al no existir regla jurídica alguna que establezca cómo debe ser aquélla o a qué parámetros debe ajustarse, se abre la mano a la más absoluta discrecionalidad judicial ${ }^{12}$. Tampoco cabrá ejercer control alguno, porque, haga lo que haga el juez -dentro de los anchísimos márgenes de la racionalidad-, no podrá ser jamás constitutivo de infracción legal alguna. Partiendo de la base de que los jueces no disparatan, llegamos a un resultado parecido al que alcanzábamos con la hipótesis anterior.

Necesitados de poner puertas al campo, se ha afirmado con demasiada convicción que esta prueba no sólo se valora, sino que debe hacerse con arreglo a las reglas de la sana crítica ${ }^{13}$. Colmada la laguna —a mi parecer, axiológica ${ }^{14}$ — un poco a la ligera, tampoco salimos mejor parados si consideramos —en un ejercicio de sinceridad- que ese criterio valorativo es tan gaseoso e inaprehensible en la práctica, que tanto da decir eso que permitirle al juez actuar con total discrecionalidad. Amén de

\footnotetext{
${ }^{8}$ Arts. 316 -interrogatorio de partes-, 319 y 326 -documentos-, 348 -prueba pericial- y 376 -testificalLEC.

${ }^{9}$ Como describe, con cita de diversos autores, ABEL LLUCH, X., en La valoración de la prueba en el proceso civil, Madrid, 2014, pp. 142-143.

${ }^{10}$ Cfr. PICATOSTE BOBILLO, J., "La prueba de reconocimiento judicial en la nueva LEC 1/2000", Revista Xurídica Galega, nº 35, 2002, p. 81.

${ }^{11}$ Cfr. GARBERÍ LLOBREGAT, J., Derecho Procesal Civil, Barcelona, 2015, p. 514.

${ }^{12} \mathrm{Cfr}$. STS, Sala $1^{\mathrm{a}}$, de 16 de abril de 1990, fj $7^{\circ}$ (RJ 1990, 2719). En cuanto a la doctrina, véase, por todos, LÓPEZ YAGÜES, V., La prueba de reconocimiento judicial en el proceso civil, Madrid, 2005, p. 296.

13 Por todos, LÓPEZ YAGÜES, V., La prueba, cit., p. 296, ABEL LLUCH, X., La valoración, cit., p. 143 o NIÑO ESTÉBANEZ, R., "Del reconocimiento judicial”, en VV. AA., Comentarios a la Ley de Enjuiciamiento Civil (F. Toribios Fuentes, Dir.), Valladolid, 2012, p. 586. Por su parte, GUTIÉRREZ SANZ, M. R., "El reconocimiento judicial”, en VV. AA., Comentarios prácticos a la nueva Ley de Enjuiciamiento Civil (J. C. Cabañas, Coord.), Madrid, 2000, pp. 362-363, va más allá y llega a sostener que esto es tan evidente que ni hace falta norma que lo establezca, por eso no hay. En general, sobre las reglas de la sana crítica, véase, por extenso, el riguroso trabajo de ABEL LLUCH, X., Las reglas de la sana crítica, Madrid, 2015.

14 Sobre la temática de las lagunas normativas, de forma sintética, pero muy didáctica, consúltese GARCÍA AMADO, J. A., Razonamiento jurídico y argumentación. Nociones introductorias, León, 2012, pp. 33-37; para un estudio en profundidad, me remito a VV. AA., Las lagunas en el Derecho, Madrid, 2005.
} 
lo anterior, siempre va a ser difícil sostener un eventual futuro recurso basado en la infracción de una norma legal que no existe y que se ha alumbrado analógicamente.

El problema que me ocupa (en el supuesto de aceptar que sí se valora esta prueba, aunque sin sujeción a criterios específicos) cobra mayores proporciones si nos cuestionamos cuál sea el objeto de la actividad valorativa y en qué sentido debe entenderse eso de «valorar». En esto hay opiniones de muy diversa índole. Algunos se han referido al acta que se levanta con ocasión de la práctica de la prueba ${ }^{15}$. Otros lo han restringido a los contenidos de la misma ${ }^{16}$. Esta faceta — que podría parecer que es inofensiva en términos prácticos - abre numerosos interrogantes desde la perspectiva del control de las decisiones judiciales sobre esta prueba en sede de recursos.

Una última prolongación del problema central que se ha tomado como objeto de estudio es la relacionada con los supuestos en que existe disociación entre el juez percipiente y el juez decisor —o sentenciador- Lo mismo —o muy parecido— sería que, en lugar de este último, aludiéramos al juez revisor (en alusión, específicamente, al tribunal de apelación civil). Este asunto ha levantado una gran polvareda que, a mi modo de ver, no se ha disipado todavía.

Descrito el colosal problema teórico y práctico — que no pseudoproblemaque afecta a esta prueba, he considerado imprescindible efectuar una aproximación al reconocimiento judicial, en el proceso civil, desprovista de apriorismos conceptuales, terminológicos y semánticos —en la medida de lo razonablemente posible-. Me considero persuadido de que una mirada objetiva, descriptiva y estrictamente epistémica, permitirá arrojar algo de luz a todo este embrollo que acabo de apuntar.

\section{APROXIMACIÓN EPISTÉMICA A LA PRUEBA DE RECONOCIMIENTO JUDICIAL}

Estimo lugar común la afirmación de que el reconocimiento judicial consiste en una actividad procesal probatoria consistente en la traslación de información (directa o indirectamente relacionada con determinada afirmación de hecho controvertida) al juez (perceptor) ${ }^{17}$. No me cabe la menor duda de que el juez (perceptor) es el absoluto protagonista de esta actividad. La información va dirigida a él, es su destinatario, en el transcurso de un acto procesal oral, sujeto a distintas formalidades previstas en la ley procesal civil. Ciertamente, como el lector seguramente se habrá figurado, lo mismo exactamente igual- acontece con un testigo que depone en presencia judicial o con un documento que lee directamente el juez.

\footnotetext{
${ }^{15}$ Como ha sostenido, entre otros, ABEL LLUCH, X., Derecho probatorio, cit., p. 1142.

${ }^{16}$ Por todos, véase RIFÁ SOLER, J. M., "Del reconocimiento judicial”, en VV. AA., Comentarios a la nueva Ley de Enjuiciamiento Civil (M. A. Fernández-Ballesteros, J. M. Rifá Soler y J. F. Valls Gombau, Coords.), tomo I, Barcelona, 2000, p. 1665.

${ }^{17}$ La expresión técnico-jurídica adecuada, procesalmente hablando, para tal descripción, es la de medio de prueba. Y así lo consideran la mayoría de autores, según la exhaustiva reseña de ABEL LLUCH, X., Derecho probatorio, cit., pp. 1037-1038.
} 
La información la recibe el juez (perceptor) de su exterior, por cualquiera de sus sentidos (de uno o de varios al mismo tiempo). Dicha información proviene de la realidad material - física - que es objeto de reconocimiento (sea una persona, una cosa, o un lugar). Así pues, la fuente de la información es la aludida realidad material, física, externa a la persona del juez (percipiente) ${ }^{18}$. Entre la realidad material y el destinatario de la información no se interpone nadie —un testigo o una de las partes-, ni nada —un documento o una grabación audiovisual-. En este sentido, no hay intermediarios entre esa realidad material percibida y el sujeto perceptor. De aquí que se la haya considerado la única prueba estrictamente directa.

El juez percibe — capta - la información, la procesa intelectualmente y la verbaliza para que, a su vez, la reciba el Letrado de la Administración de Justicia por el sentido del oído y transcriba la expresión del juez en un acta manuscrita (dejemos de lado, por un tiempo, que, además, se registre la actividad procesal gracias a aparatos de grabación audiovisual).

Una —la, quizás, mayor - singularidad de esta actividad probatoria radica en que la información que recibe el juez (perceptor) no le llega verbalizada —recibe imágenes, sonidos, olores...- y él, al procesarla, la codifica en lenguaje humano, siendo esto último lo que verbaliza ${ }^{19}$.

En el proceso descrito se advierten los siguientes riesgos de falencia: error de percepción por parte del juez ${ }^{20}$; error de codificación de lo percibido, por éste, en términos de lenguaje humano; error de percepción -y/o de intelección- auditiva en la persona del Letrado de la Administración de Justicia; y, por último, error de transcripción cometido por este último ${ }^{21}$. Lo mismo puede acontecer en relación con el interrogatorio de un testigo o de un perito (en sala de vistas), pero a menor escala por cuanto no se levanta acta manuscrita por el Letrado de la Administración de Justicia.

Justo es reconocer, por otra parte, que esos riesgos se mantienen a un nivel sumamente bajo $^{22}$, por la sencilla razón de que, por lo general, las dos figuras mencionadas no están solas y a los demás asistentes se les da el uso de la palabra para que manifiesten lo que tengan por conveniente (con frecuencia, para mostrar su discrepancia con lo verbalizado por el juez o con lo transcrito por el Letrado de la Administración de Justicia) ${ }^{23}$. Por tanto, en las pocas ocasiones en que se adviertan tales

\footnotetext{
${ }^{18}$ Me adhiero a la disyunción entre fuente y medio de prueba en la prueba de reconocimiento judicial, que efectúa MONTERO AROCA, J., en su obra La prueba en el proceso civil, $7^{\mathrm{a}}$ ed., Cizur Menor (Navarra), 2012, pp. 435-436.

${ }^{19}$ Cfr. NIEVA FENOLL, J., La valoración, cit., pp. 333-334.

20 El error de percepción no obedece sólo a deficiencias inherentes a sus sentidos, pasajeras o permanentes, sino que también puede consistir en una percepción parcial, incompleta o de algún modo sesgada, como apunta ABEL LLUCH, X., Derecho probatorio, cit., p. 1135.

${ }^{21}$ Sobre los riesgos, en general, véase ABEL LLUCH, X., Derecho probatorio, cit., p. 1135. Sobre los que atañen particularmente al Letrado de la Administración de Justicia, me remito a LÓPEZ YAGÜES, V., La prueba, cit., p. 295.

${ }^{22}$ Como apuntó RIFÁ SOLER, J. M., “Del reconocimiento”, cit., p. 1665, «obviamente, por lo general, coincidirá lo que el juez percibió con lo que conste en el acta».

${ }^{23}$ Cfr. ABEL LLUCH, X., Derecho probatorio, cit., p. 1089.
} 
defectos -necesariamente in actu-, se podrán poner de manifiesto. Y si los aludidos se resisten a mudar lo dicho o lo escrito, queda denunciada la discordancia, desde ese mismo instante.

Además, y como regla general —por no decir siempre—, el carácter imparcial del juez ${ }^{24}$ conlleva que todo lo que perciba lo verbalizará, en el bien entendido de que no se reservará nada para sí. $\mathrm{O}$, al menos, no debiera.

La práctica de la prueba concluye con la firma del acta, una vez registrado todo lo que los asistentes hayan expresado - a excepción del Letrado de la Administración de Justicia-.

Pasado un tiempo — que puede ser más o menos largo—, el juez —que no tiene que ser el mismo que practicó el reconocimiento judicial- se dispone a dictar sentencia ${ }^{25}$.

Pongamos que, para la prueba de una determinada afirmación de hecho controvertida, la información obtenida con ocasión de la práctica del reconocimiento judicial opera como prueba directa. Lo percibido — reflejado en el acta — podrá coincidir, o no, con dicha afirmación factual disputada. La labor judicial en este trance es bien sencilla: comparar una (o unas) y otra (u otras) informaciones fácticas, la percibida y la controvertida y determinar si existe identidad o disparidad. En este punto se advierte un riesgo al que no nos podemos sustraer. Podría pensarse que tal ejercicio intelectivo del juez es automático. En cualquier caso, exento de reflexión reposada. Visto así no hay ejercicio valorativo que valga ${ }^{26}$. $\mathrm{Al}$ menos en apariencia.

Lo que no tendría sentido en este concreto trance del proceso de formación de la decisión judicial es que se le pidiera al juez que se «auto-examinara» y se cuestionara - a sí mismo- la calidad de la percepción otrora efectuada o de su subsiguiente verbalización. Si antes de practicar la prueba, el juez (perceptor) ya conocía de alguna limitación o de algún defecto sensorial, lo natural es que lo hubiese manifestado a las partes. Por cierto, esta posibilidad - pensemos, por ejemplo, en un juzgador que padece alguna clase de minusvalía visual - suscita una problemática sumamente interesante, que tenemos que dejar para mejor ocasión ${ }^{27}$.

$\mathrm{Si}$, por el contrario, el juez no es consciente de su limitación sensorial, porque es transitoria, o puntual -un resfriado que le ha ocasionado cierta obturación de las vías nasales y la percepción es olfativa, por ejemplo-, y su percepción adolece de

\footnotetext{
${ }^{24}$ Cfr. ABEL LLUCH, X., Derecho probatorio, cit., p. 1130.

${ }^{25}$ Destaca esta circunstancia SOLÉ RIERA, J., "Valoración del reconocimiento”, en VV. AA., La prueba de reconocimiento judicial (X. Abel Lluch y J. Picó i Junoy, Dirs., N. Ginés Castellet, Coord.), Barcelona, 2012, p. 438.

${ }^{26}$ Por eso GÓMEZ COLOMER, J. L., "La prueba de reconocimiento judicial”, en VV. AA., El nuevo proceso civil (Ley 1/2000), Valencia, 2000, p. 329, afirma que el juez no puede sustraerse a declarar probado lo que ha percibido previamente.

${ }^{27}$ Sobre esta interesante cuestión me remito a GARCIMARTín MONTERO, R., El objeto de la prueba en el proceso civil, Barcelona, 1997, p. 227.
} 
deficiencias, lo que sucederá es que los asistentes al acto procesal de reconocimiento a excepción del Letrado de la Administración de Justicia- podrán de manifiesto su divergencia con respecto a lo que el juez manifiesta percibir - con respecto a lo que ellos han percibido, a su vez-. Lo más probable es que el juez se cuestione —allí y entonces sí- la calidad efectiva de su percepción. O, más sencillamente, puede que padezca un comprensible lapsus calami y exprese que lo que a todas luces es verde, lo percibe amarillo. En definitiva, ese «auto-examen» será concomitante con la práctica de la prueba e, incluso, antecedente, pero no tiene el menor sentido que puesto a dictar sentencia aborde tal valoración «autocrítica» ${ }^{28}$. Y aunque se cuestionase las discrepancias manifestadas por los asistentes, mal momento es éste para tal juicio, si resulta que ya no tiene delante la realidad que fuera objeto de percepción ${ }^{29}$.

Descartada esa suerte de «auto-valoración» —o «auto-examen judicial»—, cabe preguntarse si lo que es objeto de escrutinio crítico es el acta levantada con ocasión de la práctica del reconocimiento judicial ${ }^{30}$. Me da la sensación de que la respuesta discurre por los mismos derroteros que la anterior. Poco sentido tiene, en mi opinión, ponerse a escudriñar el acta al tiempo de dictarse sentencia, en busca de deficiencias de la misma. Y más que el acta, lo que se examinaría sería el contenido de la misma y, particularmente, los dichos del juez allí reproducidos ${ }^{31}$. Porque mal estará que algo que manifestó entonces, ahora, tiempo después, y habiendo perdido, obviamente, la inmediación con el objeto de reconocimiento, se percate de que no quiso decir eso, no percibió eso o sencillamente se cuestione sus palabras. Esta verificación sólo cabe, en buena lógica, en el mismo momento en que habiendo concluido el reconocimiento, el juez comprueba -con la lectura del acta- si ésta se ciñe, o no, y en qué medida, a sus manifestaciones previas. También puede suceder que sean los asistentes -que tienen voz- los que hagan ver al juez que lo dicho por éste no es compatible con lo percibido por él mismo, desde luego, y por las demás personas presentes.

Cuestión distinta es que el juez se empecine en mantener el contenido del acta incólume a pesar de las discrepancias registradas. El tratamiento procesal de esa posible disfunción es harina de otro costal. Lo que desde luego se me antoja inadmisible es que el juez, al tiempo de sentenciar, le dé por apartarse del contenido del acta —en lo que a

\footnotetext{
${ }^{28}$ Cfr. MUÑOZ SABATÉ, LL., Fundamentos de Prueba Judicial Civil L.E.C. 1/2000, Barcelona, 2000, p. 386, quien, con acierto, afirma que no parece lógico que contradiga en la sentencia lo que percibió previamente. Por su parte, ABEL LLUCH, X., Derecho probatorio, cit., p. 1136, admite la posibilidad de que el error sea advertido con posterioridad, aunque no explica cómo podría ser posible tal advertencia posterior.

${ }^{29}$ En este punto, ABEL LLUCH, X., Derecho probatorio, cit., p. 1136, ofrece dos soluciones, a mi juicio, escasamente viables. O bien acordar diligencias finales - ex art. 435.2 LEC-, o bien que las partes recurrentes en apelación insten la repetición de la prueba - ex art. 460.1.2 ${ }^{\circ}$ LEC — (suponiendo que el juez a quo haya reconocido su error en la sentencia).

${ }^{30}$ Como ha sostenido, entre otros, ABEL LLUCH, X., Derecho probatorio, cit., p. 1142, o SOLÉ RIERA, J., "Valoración”, cit., p. 441, quien, significativamente, titula uno de los epígrafes de su trabajo "valoración del acta por juez distinto".

${ }^{31}$ Los datos consignados en el acta es lo que se valora, según SOLÉ RIERA, J., "Valoración”, cit., p. 440, ó FERNÁNDEZ VAQUERO, J. L., "Del reconocimiento judicial”, en VV. AA., Comentarios a la Ley de Enjuiciamiento Civil (F. Marín Castán, Dir., y M. A. de Andrés Herrero, Coord.), tomo II, Valencia, 2015, p. 1745.
} 
él le atañe - porque recuerda —o se lo parece- que, en realidad, las cosas eran distintas a como constan recogidas en el acta. Desde un punto de vista epistemológico, me parece poco discutible que será más fiable lo que expresara en el propio acto a la vista del objeto de reconocimiento que lo que, tiempo después, le ha venido a la cabeza, distinto en alguna medida a lo manifestado originariamente. Y tanto da si apreció un dato extrínseco objetivo — el color o la forma de una máquina, por ejemplo- como un dato igualmente extrínseco, pero de corte «subjetivo», como un olor o el carácter molesto de un sonido ${ }^{32}$.

Un paralelismo contribuirá —-me parece — a hacer más nítida la consideración anterior. Un testigo es interrogado. Lo expresado por éste se recoge en un soporte digital donde se registra la grabación audiovisual. A la hora de dictar sentencia, el juez no analiza críticamente el disco compacto — desde luego nunca como objeto, en sí mismo considerado-, pero tampoco la fidelidad de la grabación, apoyándose en su memoria o en sus notas. Me adelanto a dos posibles objeciones.

La primera estriba en que lo que sí cabría es que el juez tomara pie en anotaciones sobre elementos de lenguaje no verbal inapreciables en el disco compacto - aunque me manifiesto rotundamente contrario a esa posibilidad y a todo lo que ello encierra- La respuesta a dicha objeción es que lo esencial es que lo que se oye en la grabación audiovisual que dice el testigo no lo podría discutir el juez porque recuerde que manifestó algo que no se aprecia en el audio.

La segunda de las objeciones anunciadas radica en que una cosa es una grabación audiovisual y otra, bastante distinta en cuanto a fiabilidad, es un acta levantada — habitualmente de forma manuscrita - por el Letrado de la Administración de Justicia. Pero a esto respondo con una observación elemental pero que no podemos soslayar. La práctica de la prueba debe culminar, siempre, con una revisión exhaustiva y minuciosa del contenido del acta, a fin y efecto de realizar cuantas correcciones sean precisas. Vamos, que, en último término, lo que recoja el acta debe ser, en un escenario ideal, fiel reflejo de lo que expresaron todos los presentes — con uso de la palabra-. Añádase a todo esto que, por poco tiempo que haya transcurrido, la memoria humana, de por sí frágil, puede haber experimentado algún grado de deterioro ${ }^{33}$. Y lo que no tiene mucho sentido es que en el momento le pareciese al juez todo bien, y ahora, después, y sin posibilidades de contradicción, se enmiende la plana a sí mismo, porque ahora se acuerda de que donde manifestó equis, debió haber expresado zeta ${ }^{34}$.

Hasta aquí creo que podemos sacar en claro que, en la práctica, ni el juez se examina críticamente a sí mismo (su fiabilidad, quiero decir) — ni sentido tendría que lo hiciera-, ni examina críticamente la fidelidad del acta $\_0$, mejor, de su contenido-

\footnotetext{
${ }^{32}$ En este sentido, rechazo la diferencia que establece sobre ambos tipos FONT SERRA, E., El dictamen de peritos y el reconocimiento judicial en el proceso civil, Madrid, 2000, pp. 265-266 y que se encuentra también en SOLÉ RIERA, J., "Valoración”, cit., p. 443, o en NIÑO ESTÉBANEZ, R., "Del reconocimiento", cit., p. 587.

${ }^{33}$ Así, NIEVA FENOLL, J., La valoración, cit., p. 335, o SOLÉ RIERA, J., "Valoración”, cit., p. 438.

${ }^{34}$ En este sentido, MONTERO AROCA, J., La prueba, cit., pp. 466-467, o MUÑOZ SABATÉ, LL., Fundamentos, cit., p. 386.
} 
con respecto a lo que él recuerde —o le parezca — haber expresado. Ambos exámenes críticos - que, por supuesto, se antojan sumamente saludables - deben ser simultáneos, o incluso antecedentes en algún caso, a la práctica de la prueba, pero jamás posteriores. Dejo para otra ocasión la peliaguda cuestión de si cabe revisar el acta, en el momento de dictar sentencia, a la vista del contenido de la posible grabación audiovisual efectuada en el transcurso de la prueba.

Pese a tanta disquisición, mucho me temo que seguimos sin saber qué se valora y tan siquiera si hay realmente valoración. No obstante, antes de proseguir con la reflexión, resulta obligado hacer otro alto en el camino para introducir un escenario, ligeramente distinto al anterior, pero que, a mi modo de ver, induce a confusión.

Antes partíamos del supuesto en que el enunciado fáctico controvertido - a probar - y la información obtenida con el reconocimiento judicial eran homogéneos, y lo que hacía el juez era sencillamente comparar una información con otra y concluir su identidad o su disparidad. Decíamos que, en este sentido, la prueba de reconocimiento judicial era directa. Pero también puede operar como prueba indirecta ${ }^{35}$. El enunciado fáctico controvertido - a probar - y la información obtenida con el reconocimiento judicial son heterogéneos. Ésta última constituye un indicio (o un cúmulo de ellos) a partir del cual construir una inferencia presuntiva - una presunción judicial o legal, ex arts. 386 y 385 LEC - que tenga como conclusión precisamente el factum probandum. Piénsese, por ejemplo, entre otros muchos supuestos, en un litigio que verse sobre el no uso de una vivienda o de un local. Se interesa el reconocimiento judicial y el juez observa, de forma inmediata e inmediada ${ }^{36}$, una serie de elementos fácticos que, por su experiencia y conocimiento sobre el uso y el desuso de viviendas o locales, le lleva a inferir una cosa o la otra ${ }^{37}$.

A los efectos que nos ocupan, me interesa sobremanera deslindar el ejercicio intelectual que supone la construcción de la presunción por parte del juez y el resultado objetivo de la prueba de reconocimiento judicial contenido en el acta. Y sólo diferenciando ambas con precisión quirúrgica, podremos compartir que se diga, en un determinado supuesto, como el antes descrito, que el juez no se sujete a la resultancia de la prueba de reconocimiento para poder considerar probado, o no probado, el enunciado fáctico controvertido. Precisamente, lo percibido con ocasión del reconocimiento puede operar como indicio —o como material indiciario - de una inferencia que conduce a una conclusión incompatible con el factum probandum. O puede ser también que, puesto en relación con otras informaciones obtenidas de otras fuentes de prueba, se abone una conclusión diferente a la pretendida por la parte que afirmó e intentó probar.

Lo que en definitiva quiero matizar — poniéndole mucho énfasis - es que, en este escenario, el juez no se «aparta» del resultado de la prueba de reconocimiento

\footnotetext{
35 Contempla este enfoque, entre otros, CORDÓN MORENO, F., “Del reconocimiento judicial”, en Comentarios a la Ley de Enjuiciamiento Civil (F. Cordón Moreno, T. Armenta Deu, J. J. Muerza Esparza, e I. Tapia Fernández, Coords.), vol. I (arts. 1 a 516), 2ª ed., Cizur Menor (Navarra), 2011, p. 1528.

${ }^{36}$ Cfr. ABEL LLUCH, X., Derecho probatorio, cit., p. 1034.

${ }^{37}$ Véase MUÑOZ SABATÉ, LL., Summa de probática civil, $3^{\mathrm{a}}$ ed., Madrid, 2018, pp. 135-138. Anu Fac Der UDC, 2019, 23: 50-69
} 
judicial $^{38}$ a la vez que no se encuentra rígidamente «sujeto» a las posibles derivadas que la parte interesada pretendía que se extrajeran del resultado del reconocimiento. En definitiva, no es un problema de este último, sino de los razonamientos presuntivos que vienen después relacionados, más o menos, con el resultado de dicha prueba ${ }^{39}$. Evidentemente, el cuestionamiento de esas presunciones ex post no puede confundirse con la valoración de la prueba de reconocimiento judicial, en sí misma considerada.

Vuelvo a echar mano de los paralelismos. Si lo que expresa un testigo - la información que proporciona - es homogénea con la proposición fáctica controvertida y existe identidad substancial entre ambas, podrá tenerse por probada la segunda. Y al contrario. Por otro lado, si ambas informaciones son heterogéneas y sobre la base de lo manifestado por el testigo el juez construye — o valida — una presunción, es llano que el juez tendrá que dar dos pasos distintos. Uno que atañe al testigo en cuanto a su fiabilidad propia, como fuente de información. Otro que afecta al razonamiento presuntivo que construya sobre la base del mensaje del testigo, que operará como indicio en este segundo momento. A nadie se le pasará por la cabeza confundir una cosa con otra.

Y siguiendo con el paralelismo, conviene preguntarse por qué un juez asume - o rechaza - la información que le proporciona un testigo — sea homogénea o heterogénea con el enunciado fáctico controvertido- . Desde luego, el juez cabal no la asumirá —o rechazará- sin más. Existe un juicio crítico, por elemental que sea ${ }^{40}$. Tal asunción de la información proporcionada por el testigo, o su rechazo, se sustentarán en si lo reputa fiable, o no fiable ${ }^{41}$. Sobre la base del contenido y otros elementos del discurso del testigo - $-\mathrm{y}$, para otros muchos, haciendo pie en su lenguaje no verbalque operan como indicios, se construirá un razonamiento presuntivo -aunque el Tribunal Supremo se empeñe en decir que es otra $\operatorname{cosa}^{42}$-, basado en máximas de experiencia sobre fiabilidad, que desembocará argumentativamente en la conclusión de la fiabilidad o su contrario.

Llegados a este punto, nos sale al paso una pregunta obligada, de carácter netamente epistémico: ¿es posible que la realidad material —objeto de reconocimiento- pueda ser reputada —en algún caso- no fiable? Respondo rotundamente que sí. Es perfectamente factible que por causas naturales y, más frecuentemente, por causas artificiales (alteración provocada, manipulación), el estado originario de algo material transmute, total o parcialmente ${ }^{43}$. Se puede decir que no es

\footnotetext{
${ }^{38}$ Es mayoritario el sector doctrinal que defiende la tesis del «apartamiento». Por todos, SOLÉ RIERA, J., "Valoración”, cit., p. 442. En cambio, para MONTERO AROCA, J., La prueba, cit., p. 466, el juez no se puede sustraer a su propia percepción previa.

${ }^{39}$ Esto lo intuyó el prof. SERRA, según LÓPEZ YAGÜES, V., La prueba, cit., p. 289.

${ }^{40}$ Cfr. ABEL LLUCH, X., Derecho probatorio, cit., p. 1046.

${ }^{41}$ Cfr. ABEL LLUCH, X., La valoración, cit., pp. 54-55.

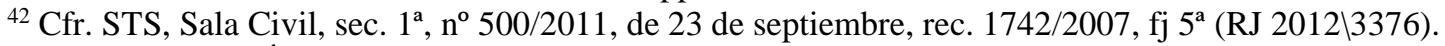

43 SERRA DOMÍNGUEZ, M., en "Reconocimiento judicial", publicado en Estudios de Derecho Probatorio, Lima, 2009, p. 560, distingue -lo que comparto tal cual él lo formula- que se puede dar un error de percepción de doble naturaleza: subjetivo -por ser atribuible al juez- y objetivo, resultante de que las partes hayan falseado la realidad-. A este respecto, me parece sumamente ilustrativo el gráfico ejemplo de la jaula de conejos que refiere ABEL LLUCH, X., Derecho probatorio, cit., p. 1135. En Anu Fac Der UDC, 2019, 23: 50-69
} 
auténtico porque lo que era, ya no es. La fuente de prueba no es genuina, al haber sufrido una transformación, de modo que la información que proporciona —en el acto de percepción judicial - no se corresponde con la realidad auténtica, originaria, que posiblemente fuera la que motivó el litigio en consonancia con la fisonomía que tenía entonces y no ahora.

Piénsese, por poner un ejemplo, en un pleito sobre servidumbres, donde la actora alega que el predio sirviente ha realizado movimientos de tierra que dificultan la circulación por un camino, cosa que niega la demandada. Interesada la prueba de reconocimiento judicial por la primera, la segunda se afana en retirar a prisa y corriendo alguna cantidad de tierra que haga mínimamente transitable el camino. Cuando el juez (percipiente) acude al lugar y prueba a circular con su vehículo por aquél, lo hace con razonable satisfacción. La información obtenida procede de una realidad adulterada, inauténtica, y por ello no fiable. Pero determinar esto es tarea indelegable del juez.

En definitiva, hay margen para el análisis crítico de la fiabilidad de la fuente de la información — de la realidad material reconocida - en esta clase de prueba y, en consecuencia, para evaluar si se asume la información que proporciona, o se rechaza. Llámese a esto valoración - como así lo considero yo- o de cualquier otra forma, lo importante es que sí hay algo que examinar críticamente y no es ni la persona del juez perceptor, ni el contenido del acta, sino la fiabilidad de la propia fuente, susceptible de resultar inauténtica, por causas naturales o por causas artificiales.

\section{LA VALORACIÓN DE LA PRUEBA DE RECONOCIMIENTO JUDICIAL A FONDO}

Me parece exento de discusión que la actividad valorativa es estrictamente intelectual. En lo que no hay excesivo consenso es en la naturaleza de la misma. Tengo para mí que se trata de un razonamiento de naturaleza presuntiva ${ }^{44}$.

La finalidad que persigue la valoración es, en mi opinión, y como ya he avanzado, determinar la fiabilidad de la fuente de prueba, en este caso, de la realidad objeto de reconocimiento. Y, más exactamente, se trata de determinar si dicha realidad material es auténtica, o no, porque, en este último caso, haya sido objeto de manipulación, alteración o adulteración.

Para alcanzar dicho juicio racional, el juez tomará la información desprendida de la propia fuente de prueba durante el desarrollo de la actividad probatoria. Cuanto más rico y meticuloso sea el ejercicio de «aprehensión sensorial» ${ }^{45}$, tanto mejor será la posterior valoración. Porque no sólo deberá prestar atención el juez a lo que le transmite

general, sobre la posibilidad de manipulación de la realidad, se han manifestado, entre otros, SOLÉ RIERA, J., "Valoración”, cit., p. 441, LÓPEZ YAGÜES, V., La prueba, cit., p. 295, ó NIEVA FENOLL, J., La valoración, cit., p. 338.

${ }^{44}$ Me remito, sobre esta compleja cuestión, a MUÑOZ SABATÉ, LL., La prueba de indicios en el proceso judicial, Madrid, 2016, pp. 24-31.

${ }^{45}$ Sobre las distintas definiciones del reconocimiento judicial, ABEL LLUCH, X., Derecho probatorio, cit., pp. 1040-1042. 
la realidad reconocida sobre sí misma, sino que tendrá que reparar en la información que atienda a la integridad —o la alteración — de la fuente misma. Todo ello, una información y otra, deberá ser verbalizado y plasmado en el acta levantada por el Letrado de la Administración de Justicia.

Llegados al momento de dictar sentencia, el juez adoptará su decisión valorativa en función, en primer lugar, de los indicios que, desprendidos durante el transcurso del reconocimiento, se hallen disponibles en el acta. Y, en segundo lugar, dichos indicios los pasará por el tamiz de sus máximas de experiencia sobre la integridad de la realidad observada -0 , a la inversa, sobre las manifestaciones típicas de manipulación o alteración-. Así pues, se trata, a todas luces, de un ejercicio valorativo libérrimo ${ }^{46}$, casi imposible de tasar, diría yo, por su propia idiosincrasia. Por consiguiente, estimo necesario que en la LEC se introdujera una norma específica sobre la valoración de este medio de prueba, tal cual acontece con los testigos o con los peritos.

Expuesto lo anterior, conviene detenerse en unos cuantos -pocos- asuntos a mi juicio espinosos. El primero de ellos atiende a la posibilidad de que los indicios, de los que parta el juez (sentenciador) para construir su juicio valorativo, no se hallen recogidos en el acta — porque, por alguna razón, no los verbalizara al tiempo de practicarse el reconocimiento-, pero sí se registrasen en su memoria. Por consiguiente, el juez no se encuentra vinculado al contenido del acta ${ }^{47}$. LÓPEZ YAGÜES matiza afirmando que esa posible desvinculación no es posible cuando se trate de datos objetivos e irrefutables $^{48}$. La tesis de la no sujeción se sustancia en tres argumentos ${ }^{49}$ : (a) puede producirse un error perceptivo ${ }^{50}$, en cuyo caso me pregunto cómo sale, tiempo después y una vez perdida la inmediación, del supuesto error; (b) porque además de lo percibido, están las máximas de experiencia que aplique el juzgador, que podrían, entiendo yo, distorsionar o completar el resultado del acto perceptivo, aunque reconozco que no soy capaz de comprender cómo; (c) porque la mencionada resultancia del acto perceptivo puede verse afectada al contrastarla con el resto de pruebas. Ninguno de los tres argumentos me parece aceptable.

Como he dicho, si hubo un error perceptivo, que no se solventó in actu, es imposible que se corrija después, salvo que el juez vuelva a reconocer la concreta realidad. Las máximas de experiencia son regularidades fenomenológicas condensadas en reglas no jurídicas, lo que es por completo distinto a las percepciones resultantes del contacto directo con el objeto de prueba. En todo caso, merced a las máximas de experiencia podremos cuestionar la fiabilidad de la fuente de prueba, pero no el acto perceptivo mismo. Desde luego no en el trance de dictar sentencia. Quizás sí al momento de percibir, cuestionándose el acierto de lo aprehendido por los sentidos, que mueva al juez a revisar su percepción. Finalmente, si el resto de pruebas apunta en una

\footnotetext{
${ }^{46}$ Por todos, ABEL LLUCH, X., Derecho probatorio, cit., p. 1131.

${ }^{47}$ Cfr. SAP La Rioja, $n^{\circ}$ 117/2001, de 3 de marzo, fj $2^{\circ}$ (RJ 2001\165858) y ABEL LLUCH, X., Derecho probatorio, cit., p. 1130.

${ }^{48}$ Cfr. LÓPEZ YAGÜES, V., La prueba, cit., p. 301.

49 Ídem.

${ }^{50}$ Cfr. ABEL LLUCH, X., Derecho probatorio, cit., p. 1134.
}

Anu Fac Der UDC, 2019, 23: 50-69 
dirección distinta al resultado del reconocimiento no será porque haya que desconfiar de la percepción judicial sino porque la fuente de prueba no será auténtica, lo cual es completamente distinto.

Frente a quienes sostienen que el juez puede «escapar» al contenido del acta (mejor dicho, a su propia percepción verbalizada), argumento que genera una inseguridad jurídica inaceptable. Por supuesto que es posible que esto ocurra —máxime cuando las manifestaciones del juez son manuscritas por el Letrado de la Administración de Justicia-, pero se antoja sumamente peligroso dar entrada a estas percepciones supuestamente recordadas — que no expresadas en su momento—, porque implica asumir un riesgo considerable de que ese pretendido recuerdo quizás haya nacido ex post, sin la menor malicia, por supuesto ${ }^{51}$. No existen, en definitiva, garantías de que eso se corresponda con una percepción real habida en el momento del reconocimiento y no con un «recuerdo» surgido con posterioridad por influencia de numerosos factores que, con frecuencia, «crean» falsos recuerdos.

Distinto tratamiento merece, según entiendo, la circunstancia de que un indicio no fuera objeto de expresión oral por el juez y, sin embargo, sí se desprenda — sin duda - de la grabación audiovisual simultánea, cuyo soporte obre unido a las actuaciones. Considero que debería tomarse en consideración porque, en tanto no se supere la discordancia existente entre los arts. 358 y 359 LEC, y atendido el derecho fundamental a la prueba — ex art. 24.2 CE—, la prueba debe maximizarse, nunca restringirse o escatimar en su contenido por formalismos exasperantes.

El segundo de los asuntos espinosos, que anunciaba antes, atañe a las máximas de experiencia que el juez deberá emplear indispensablemente para juzgar la fiabilidad — o, mejor, la autenticidad- de la realidad reconocida ${ }^{52}$. Con una enorme frecuencia, dichas máximas serán de carácter especializado, asequibles exclusivamente a «comunidades de expertos» ${ }^{53}$. Si, como suele acontecer, el reconocimiento se practica sin el acompañamiento de un perito - fuera del supuesto del art. 356 LEC—, la fuente de conocimientos del juez será su propia experiencia, que no sabemos cuál es —por lo general - y cuya calidad epistémica será —comúnmente - dudosa. Una consecuencia de este problema — preocupante - es que si carece de tales máximas de experiencia especializadas, tampoco le resultará posible advertir los indicios correspondientes. Simplemente, no será capaz de apreciar las señales que ve, pero no es capaz de captar. O puede ocurrir, también, que aprecie indicios que realmente no son tales o no son indicadores de nada objetivo.

\footnotetext{
51 Sobre el mecanismo del olvido, así como de los falsos recuerdos, vid. MANZANERO, A. L., Psicología del testimonio. Una aplicación de los estudios sobre la memoria, Madrid, 2008, pp.83-90 y 125-135; del mismo autor, Memoria de testigos. Obtención y valoración de la prueba testifical, Madrid, 2010, pp. 65-81.

52 Como dijera FONT SERRA, E., El dictamen, cit., p. 213, se produce una «(...) reelaboración de lo percibido, a través de las máximas de experiencia, que permite al juez razonar en torno a lo percibido».

${ }^{53}$ Sobre esta cuestión, véase VÁZQUEZ, C., "La admisibilidad de las pruebas periciales y la racionalidad de las decisiones judiciales”, Doxa. Cuadernos de Filosofía del Derecho, nº 38, 2015, p. 108.
} 
Estrechamente conectado con lo anterior está el problema de la validación de la fiabilidad de la fuente de prueba por ausencia de razones en sentido contrario. Favorecido por el desconocimiento —o carencia— de máximas de experiencia especializadas —en torno a la manipulación de la realidad material—, el juez no apreciará por lo general señales o signos que le deban conducir a la desconfianza —o a una confianza objetivamente fundada ${ }^{54}$ - . Lo que se traducirá en un juicio falaz. Se trata de la conocida falacia ad ignorantiam, donde la ausencia de datos que desvirtúen determinada asunción, conduce derechamente a concluir en la hipótesis inicial ${ }^{55}$. Si no hay nada que al juez le haga cuestionarse la fiabilidad de la prueba, concluirá que es de plena confianza. Pero lo más posible es que no se trate de que no hay nada, sino de que el juez no es capaz de apreciar nada, lo que es completamente distinto.

De las dos cuestiones recientemente analizadas se desprende una tercera, íntimamente vinculadas a ambas y que explica, en mi opinión, que cueste tanto aceptar que en el caso del reconocimiento judicial puede -y debe- haber un ejercicio valorativo acerca de la fiabilidad de la fuente de prueba. Como el juez se encuentra, en la inmensa mayoría de los casos, desprovisto de elementos de juicio crítico - máximas de experiencia, especializadas, $y$, por tanto, de la habilidad para percatarse de la presencia de indicios-, se sitúa de forma permanente, y de forma significativa en esta prueba, en una posición de «ignorancia epistémica». Por consiguiente, casi nunca, o prácticamente nunca, concluirá en la inautenticidad de la fuente de prueba (o, lo que es lo mismo, del objeto del reconocimiento). Esa resultancia constante le conducirá, quizás inconscientemente, a formarse la idea de que en esta prueba no hay valoración (sencillamente, no cabe ${ }^{56}$. Lo que, quizás, contribuyese a explicar que una ideación de este cariz, mantenida ampliamente en el tiempo, se acabase traduciendo en la falta de inclusión, en la redacción de la LEC vigente, de un precepto que contuviese un canon valorativo, como no sucede, en cambio, con el resto de fuentes de prueba.

Otro asunto, también espinoso, porque choca con la disciplina legal de esta prueba, es que no se fomenta la práctica conjunta del reconocimiento judicial con otros medios de prueba. Quizás la realidad percibida, efectivamente inauténtica, esconde -por azar o por pericia del agente humano manipulador- cualquier indicio de alteración a la vista del sujeto percipiente (aunque me permito dudarlo de un perceptor experto). Pero es posible que, de esos otros medios de prueba, especialmente de los personales, se puedan desprender indicios de dicha alteración.

Un testigo, por ejemplo, que en su deposición da cuenta de detalles fácticos que chocan abiertamente con la idiosincrasia presente de la realidad objeto de reconocimiento. En este sentido, el art. 357 LEC se me antoja criticable por cuanto

\footnotetext{
${ }^{54}$ De aquí que, con razón, NIEVA FENOLL, J., La valoración, cit., pp. 337-338, subraye la conveniencia de la asistencia de un técnico.

${ }^{55}$ Sobre las falacias en el ámbito del razonamiento jurídico y su reflejo en la jurisprudencia, véase ANDINO LÓPEZ, J. A., "Las falacias argumentativas y su reflejo en la jurisprudencia”, Revista Jurídica de Catalunya, vol. 116, $n^{\circ}$ 4, 2017, pp. 893-908. Sobre las falacias en general, me remito a los cuidados estudios de VEGA REÑÓN, L., La fauna de las falacias, Madrid, 2013 y BORDAS SOLANAS, M., Las trampas de Circe: falacias lógicas y argumentación informal, Madrid, 2011.

${ }^{56}$ Como se sostiene en SAP Granada, sec. $3^{\mathrm{a}}$, no 954/2002, de 23 de noviembre, fj $1^{\circ}$ (JUR 2003131938).
} Anu Fac Der UDC, 2019, 23: 50-69 
somete tal conjunción de pruebas a la discreción del juez que, por criterios de gestión del tiempo, se sienta disuadido a tan conveniente práctica simultánea del reconocimiento con las testificales o con los interrogatorios de parte. Sin embargo, se le debe reconocer al legislador un gran acierto en la medida en que se plantea la práctica simultánea como unidad de acto, de modo que, a resultas de la manifestación de un testigo, puede el juez incidir en algún aspecto de la realidad objeto de reconocimiento y advertir un indicio relativo a la fiabilidad en el que no había reparado anteriormente.

Por último, quiero aludir a la — para mí- necesaria inclusión de una norma que establezca un canon valorativo para el juez ${ }^{57}$. Probablemente, haya de ser la común en el resto de pruebas, en referencia a las reglas de la sana crítica. No se me oculta que tampoco significará una ganancia sustancial para el juez, pero, sí lo será, como veremos seguidamente, para los justiciables.

\section{MOTIVACIÓN Y CONTROL DEL JUICIO VALORATIVO DE LA PRUEBA DE RECONOCIMIENTO JUDICIAL}

Si se acepta que hay realmente valoración, y en los términos y con el objeto antes descritos, debe asumirse, con arreglo a lo dispuesto en los arts. 218.2 LEC y 24.1 y 120.3 CE, que el juez viene obligado a motivar también su decisión en torno a la valoración del reconocimiento judicial, en el sentido de justificar la postura adoptada en cuanto a la fiabilidad, o no, de la fuente misma de prueba.

Por lo que hace al cuestionamiento por las partes de la valoración judicial del reconocimiento judicial en sede de recursos, quisiera dejar sentado, de entrada, que no es tal cualquier queja relativa a la disconformidad a Derecho del desarrollo de la actividad probatoria misma.

Encuentro serias dificultades para encuadrar las posibles divergencias habidas entre lo que verbalizase el juez y lo que percibiese sensorialmente el resto de asistentes en el ámbito estricto de la valoración de la prueba. Otro tanto sucede con la posibilidad de que surjan discrepancias entre lo primero - las manifestaciones judiciales - y el contenido de la grabación audiovisual que se efectuase in actu. No son, en mi opinión, errores de valoración sino de apreciación ${ }^{58}$, que, en cualquier caso, no permiten identificar fácilmente la norma procesal infringida.

\footnotetext{
${ }^{57}$ Como pide, entre otros, ABEL LLUCH, X., Derecho probatorio, cit., p. 1132, quien añade a la propia necesidad de introducir una norma, el que la misma introduzca el canon valorativo de la sujeción a las reglas de la sana crítica.

58 Por ejemplo, qué solución habría que adoptar si el juez que teóricamente debe percibir padeciera daltonismo. O si debería ser realmente obligatorio e inesquivable realizar una grabación audiovisual desde la posición del juez percipiente, teniendo entonces el legislador que sentar una suerte de jerarquía entre la grabación y al acta manuscrita, cuya elaboración podría llegarse a eliminar completamente.
}

Anu Fac Der UDC, 2019, 23: 50-69 
Tampoco es una deficiencia valorativa la falta de efectiva motivación. La ausencia de auténtica justificación es cosa que debería encauzarse mediante la denuncia de la infracción del art. 218.2 LEC ${ }^{59}$.

En mi opinión, las deficiencias en la valoración de esta prueba pueden guardar relación con los diversos elementos del razonamiento presuntivo que aquélla encierra:

(i) La efectiva inclusión en el acta levantada —con ocasión del reconocimiento- de los indicios, tomados como sustrato de la decisión judicial. Me parece sumamente cuestionable — como ya he adelantado anteriormente- que el juez pueda partir, a la hora de elaborar su juicio, de recuerdos personales sobre lo percibido en el transcurso de la prueba que, por alguna razón, no verbalizó y, por ende, no se recogieron en la referida acta ${ }^{60}$.

(ii) Debe atenderse a las máximas de experiencia —necesariamente vulgaresque el juez maneje, de ordinario implícitamente en su discurso. En mi opinión, entrañan un riesgo notable porque, por lo general, dichas máximas no serán prácticamente nunca vulgares, sino especializadas. Los signos de integridad -0 , por el contrario, de alteración - de una realidad material cualquiera, salvo que sean evidentes por burdos ${ }^{61}$, escapan a la capacidad del hombre con un nivel cultural medio.

Cuestión distinta - y desde luego preocupante — es la que atañe a la forma en que quepa denunciar tal disfunción en sede de recursos, cuando, para empezar, la demostración del carácter erróneo de la máxima de experiencia empleada implícitamente por el juez reclama inexcusablemente la aportación de una opinión experta — de un dictamen pericial, en definitiva ${ }^{62}$ -

(iii) El carácter falaz del argumento judicial que, ante la ausencia de indicadores de falta de fiabilidad de la fuente de prueba, la reputa confiable, en lugar de proporcionar razones positivas -indicios - que refuercen la conclusión positiva alcanzada. Se trata de una manifestación de la denominada falacia ad ignorantiam ${ }^{63}$.

(iv) La posibilidad de infirmar ${ }^{64}$ la conclusión judicial y la puesta de manifiesto de una duda razonable en cuanto a la fiabilidad de la fuente de prueba.

\footnotetext{
${ }^{59}$ Sobre esta cuestión, véase DE MIRANDA VÁZQUEZ, C., "La motivación del juicio de hecho: un poco de luz en un mar de sombras”, Justicia. Revista de Derecho Procesal, 2015 (2), pp. 267-308.

${ }^{60}$ Ya me he ocupado anteriormente, en este propio trabajo, de esta cuestión, con las correspondientes citas bibliográficas.

${ }^{61}$ Recuerdo un caso de la práctica forense en el que era indiscutible la alteración del objeto reconocido una máquina-: se la había pintado de otro color, pero la pintura aún estaba fresca y si se retiraba o rasgaba la capa superficial se apreciaba el verdadero tintado, el original.

62 Sobre este problema, véase DE MIRANDA VÁZQUEZ, C., "La relevancia de los indicios en la valoración de la prueba testifical”, La prueba civil: aspectos problemáticos, número monográfico de la Revista Jurídica de Catalunya, 2017, p. 85.

${ }^{63}$ Sobre dicha falacia, con más detalle, cfr. BORDES SOLANAS, Las trampas, cit., pp. 295-297.

${ }^{64}$ Como señala MUÑOZ SABATÉ, LL., en su obra La prueba de indicios en el proceso judicial, Madrid, 2016, p. 81, «la información consiste en cualquier otra conclusión oponible a una presunción o a alguna de las inferencias emanadas de algún indicio”.
} 
Con todo y haber detectado estos posibles motivos de impugnación de la valoración judicial de la prueba de reconocimiento judicial, nos sale al paso un considerable obstáculo: no hay precepto alguno que invocar como vulnerado. Claro, como no hay enunciado jurídico alguno en la Ley que fije el canon valorativo correspondiente para esta prueba, no se tiene apoyo firme para dar un paso tan serio.

Ciertamente me cuesta trabajo pensar que este concreto acto de valoración es inexpugnable a la crítica ${ }^{65}$, porque me resulta muy poco juicioso. No se me escapa que muchas voces autorizadas han abogado por considerar aplicable por analogía los demás preceptos que regulan la valoración de los demás medios de prueba - excepción hecha, claro está, por su particular idiosincrasia, de los documentos-. Más bien, lo que sostienen es que la valoración del reconocimiento judicial se sujeta a un canon implícito que es, suponen, el de la sujeción a las reglas de la sana crítica. Pongamos que sí, que cupiese esta aplicación analógica. Aun así, me sigo preguntando qué artículo debe afirmar el abogado como infringido: ¿el 376 LEC —referente a la prueba testifical一, por ejemplo? ¿o éste último, junto al 348 LEC — en relación con la pericial—? No me parece excesivamente convincente ninguna de las posibles soluciones, pero debo reconocer que no hay salida, más que ésta.

Supongamos que se nos acepta una invocación analógica de otro, u otros preceptos que tienen como común denominador la aplicación, en términos de valoración, de las reglas de la sana crítica. Esto que es solución, en principio, se nos torna rápidamente en problema, porque ni sabemos a ciencia cierta cuáles son esas reglas en el plano de la prueba de reconocimiento judicial, ni es posible —legalmente hablando - introducir prueba — pericial— en segunda instancia para soportar la inclusión de una opinión experta que desacredite las máximas de experiencia erróneamente empleadas por el juez a quo y cuáles deberían ser las que correspondería aplicar en su lugar.

Reconozco que el panorama descrito no es excesivamente halagüeño para el operador forense que, disconforme con la valoración de la prueba de reconocimiento judicial, lo plantea en la segunda instancia, con la pretensión de que se produzca una verdadera revisio prioris instantiae.

\section{V. ¿QUÉ TRASCENDENCIA TIENE QUE EL JUEZ PERCEPTOR SEA DISTINTO AL JUEZ SENTENCIADOR, EN TÉRMINOS VALORATIVOS?}

No tanta como pudiera pensarse en una primera aproximación al interrogante ${ }^{66}$. El juez percipiente se ocupará de la labor meramente percipiente — de la apreciación de

\footnotetext{
${ }^{65}$ Cfr. STS, Sala $1^{\text {a }}$, de 16 de abril de 1990 (RJ 1990, 2719). Introduce, sin embargo, una matización la STS, Sala $1^{\mathrm{a}}$, de 23 de octubre de 1999 (RJ 1999,8160), pues se limita a permitir una revisión crítica cuando constando un dato en el acta se ha prescindido de él en la sentencia.

${ }^{66}$ Contrariamente, la mayoría de la doctrina lo percibe muy negativamente, hasta el punto de que PICATOSTE BOBILLO, J., "La prueba", cit., p. 82, o RODRÍGUEZ DONCEL, N., y MORENO MEDINA, M. T., "Cuestiones sobre la prueba de reconocimiento judicial", en VV. AA., Aspectos Anu Fac Der UDC, 2019, 23: 50-69
} 
la prueba-, pero no de la valorativa. Su cometido, en su función de auxilio, se circunscribirá a percibir y verbalizar lo percibido, que se recogerá, como impone la Ley, en el acta que levante minuciosamente el Letrado de la Administración de Justicia ${ }^{67}$. No obstante, su papel no debe restringirse a una recepción mecánica del reflejo de la realidad en sus sentidos. Debe mostrarse especialmente proactivo en la localización, percepción y manifestación de todos los signos —indicios- que se desprendan de la realidad y que, posteriormente, deban servir al juez decisor para valorar rigurosamente la prueba.

Obviamente, y desde una perspectiva de lege ferenda, sería de gran ayuda que se sustituyese la mecánica actual del reconocimiento por una grabación audiovisual que, dirigida por el juez percipiente, permitiese aprehender con mayor facilidad las señales informativas que se desprenden de la propia realidad examinada ${ }^{68}$. En tal caso, el recurso a un juez auxiliar no revestiría mayor problema.

\section{BIBLIOGRAFÍA}

ABEL LLUCH, X., Derecho probatorio, Barcelona, 2012.

- La valoración de la prueba en el proceso civil, Madrid, 2014.

- Las reglas de la sana crítica, Madrid, 2015.

ANDINO LÓPEZ, J. A., "Las falacias argumentativas y su reflejo en la jurisprudencia”, Revista Jurídica de Catalunya, vol. 116, nº 4, 2017, pp. 893-908.

BORDAS SOLANAS, M., Las trampas de Circe: falacias lógicas y argumentación informal, Madrid, 2011.

CORDÓN MORENO, F., "Del reconocimiento judicial”, en Comentarios a la Ley de Enjuiciamiento Civil (F. Cordón Moreno, T. Armenta Deu, J. J. Muerza Esparza, e I. Tapia Fernández, Coords.), vol. I (arts. 1 a 516), $2^{\mathrm{a}}$ ed., Cizur Menor (Navarra), 2011, pp. 1526-1536.

DE MIRANDA VÁZQUEZ, C., "La prueba de reconocimiento judicial”, en VV. AA., Práctica Procesal Civil (J. E. Corbal Fernández, P. Izquierdo Blanco y J. Picó i Junoy, Dirs.), tomo V, $23^{\mathrm{a}}$ ed., Barcelona, 2014, pp. 4115-4167.

prácticos de la prueba civil (X. Abel Lluch y J. Picó i Junoy, Dirs.), Barcelona, 2006, p. 547, hablan de la desnaturalización de la prueba.

${ }^{67}$ Me parece muy lúcida la reflexión que se contiene en la SAP Cádiz, sec. $5^{\mathrm{a}}$, no 363/2007, de 2 de julio, rec. 43/2007, fj $1^{\circ}$ (JUR 20121247414). Subraya la importancia de que el juez perceptor realice su cometido con sumo cuidado y que se registre con todo detalle en el acta, levantada por el Letrado de la Administración de Justicia, a la que tendrá que sujetarse inexorablemente el juez sentenciador (obviamente, distinto del primero).

${ }^{68}$ Propuesta inspirada en FONS RODRÍGUEZ, C., "Reconocimiento judicial y nuevas tecnologías. ¿Puede solicitarse la prueba de un reconocimiento judicial para que el juez presencie, a través de videoconferencia, las imágenes que recoge una persona sobre un determinado lugar o espacio fuera de la circunscripción judicial y con ello evitar que se tenga que acudir al auxilio judicial?”, en VV. AA., La prueba de reconocimiento judicial (X. Abel Lluch y J. Picó i Junoy, Dirs.), Madrid, 2012, pp. 475-494. 
- "La motivación del juicio de hecho: un poco de luz en un mar de sombras", Justicia. Revista de Derecho Procesal, 2015 (2), pp. 267-308.

- "La relevancia de los indicios en la valoración de la prueba testifical”, La prueba civil: aspectos problemáticos, número monográfico de la Revista Jurídica de Catalunya, 2017, pp. 71-85.

FERNÁNDEZ VAQUERO, J. L., "Del reconocimiento judicial”, en VV. AA., Comentarios a la Ley de Enjuiciamiento Civil (F. Marín Castán, Dir., y M. A. de Andrés Herrero, Coord.), tomo II, Valencia, 2015, pp. 1743-1756.

FONT SERRA, E., El dictamen de peritos y el reconocimiento judicial en el proceso civil, Madrid, 2000.

GARBERÍ LLOBREGAT, J., Derecho Procesal Civil, Barcelona, 2015.

GARCÍA AMADO, J. A., Razonamiento jurídico y argumentación. Nociones introductorias, León, 2012.

GARCIMARTÍN MONTERO, R., El objeto de la prueba en el proceso civil, Barcelona, 1997.

GÓMEZ COLOMER, J. L., "La prueba de reconocimiento judicial”, en VV. AA., El nuevo proceso civil (Ley 1/2000), Valencia, 2000.

LÓPEZ YAGÜES, V., La prueba de reconocimiento judicial en el proceso civil, Madrid, 2005.

MANZANERO, A. L., Psicología del testimonio. Una aplicación de los estudios sobre la memoria, Madrid, 2008.

- Memoria de testigos. Obtención y valoración de la prueba testifical, Madrid, 2010.

MONTERO AROCA, J., en su obra La prueba en el proceso civil, $7^{\mathrm{a}}$ ed., Cizur Menor (Navarra), 2012.

MUÑOZ SABATÉ, LL., Fundamentos de Prueba Judicial Civil L.E.C. 1/2000, Barcelona, 2000.

- La prueba de indicios en el proceso judicial, Madrid, 2016.

- Summa de probática civil, $3^{\mathrm{a}}$ ed., Madrid, 2018.

NIEVA FENOLL, J., La valoración de la prueba, Madrid, 2010.

NIÑO ESTÉBANEZ, R., Del reconocimiento judicial, en «Comentarios a la Ley de Enjuiciamiento Civil», F. Toribios Fuentes (dir.), Valladolid, 2012, pp. 58-591.

PICATOSTE BOBILLO, J., "La prueba de reconocimiento judicial en la nueva LEC 1/2000”, Revista Xurídica Galega, nº 35, 2002. 
RIFÁ SOLER, J. M., Del reconocimiento judicial, en «Comentarios a la nueva Ley de Enjuiciamiento Civil», M. A. Fernández-Ballesteros, J. M. Rifá Soler y J. F. Valls Gombau (coords.), tomo I, edit. Iurgium, Barcelona, 2000, pp. 1640-1669.

RODRÍGUEZ DONCEL, N., y MORENO MEDINA, M. T., "Cuestiones sobre la prueba de reconocimiento judicial”, en VV. AA., Aspectos prácticos de la prueba civil (X. Abel Lluch y J. Picó i Junoy, Dirs.), Barcelona, 2006, pp. 531-552.

SERRA DOMÍNGUEZ, M., en "Reconocimiento judicial”, publicado en Estudios de Derecho Probatorio, Lima, 2009, pp. 539-571.

SOLÉ RIERA, J., "Valoración del reconocimiento", en VV. AA., La prueba de reconocimiento judicial (X. Abel Lluch y J. Picó i Junoy, Dirs., N. Ginés Castellet, Coord.), Barcelona, 2012, 249-337.

VÁZQUEZ, C., "La admisibilidad de las pruebas periciales y la racionalidad de las decisiones judiciales”, Doxa. Cuadernos de Filosofía del Derecho, n ${ }^{0} 38,2015$, pp. 101130.

VEGA REÑÓN, L., La fauna de las falacias, Madrid, 2013.

VV. AA., Las lagunas en el Derecho, Madrid, 2005. 